GENE 03590

\title{
RNA template-specific polymerase chain reaction (RS-PCR): a novel strategy to reduce dramatically false positives
}

(Recombinant DNA; carryover contamination; Xenopus insulin; reverse transcription-polymerase chain reaction)

\author{
Alan R. Shuldiner, Ajay Nirula and Jesse Roth \\ Diabetes Branch, National Institute of Diabetes and Digestive and Kidney Diseases, National Institutes of Health, Bethesda, MD 20892 (U.S.A.)
}

Received by J. Piatigorsky: 30 November 1989

Revised: 1 February 1990

Accepted: 5 February 1990

\section{SUMMARY}

We report a novel modification of the reverse transcription-polymerase chain reaction method that we have dubbed RNA template-specific PCR (RS-PCR). With this approach, the $5^{\prime}$ end of the first strand is tagged with a unique nucleotide sequence during reverse transcription which may then be exploited to amplify preferentially RNA-derived sequences. In our hands, RS-PCR greatly reduces the frequency of false positives and virtually eliminates carryover contamination from DNA fragments amplified in previous experiments.

\section{INTRODUCTION}

Reverse transcription (RT) coupled to the PCR (RT-PCR) is an extraordinarily powerful method to detect as few as one to 100 copies of a specific RNA from a single cell or a small number of cells (Kawasaki et al., 1988; Rappolee et al., 1988a,b). Unfortunately, the exquisite sensitivity of this technique presents one of its severe shortcomings, false positives resulting from contamination with minute quantities of DNA. By instituting and maintaining a meticulous laboratory technique, it is possible to reduce somewhat the frequency of false positives (Kwok and Higuchi, 1989). Nevertheless, false positives remain a major problem, especially when the high sensitivity of RT-PCR is

Correspondence to: Dr. A.R. Shuldiner, NIH, Diabetes Branch, Bldg. 10, Rm. 8-S-243, Bethesda, MD 20892 (U.S.A.) Tel. (301)496-1063; Fax (301)402-0573.

Abbreviations: bp, base pair(s); d, downstream; ds, double strand(ed); nt, nucleotide(s); oligo, oligodeoxyribonucleotide; PCR, polymerase chain reaction; RS, RNA template-specific; RT, reverse transcription or transcriptase; ss, single strand(ed); $t$, tag; $u$, upstream. exploited to detect very low abundance mRNA species. We report a novel modification of the RT-PCR method, designated RS-PCR which in our hands enormously reduces the frequency of false positives without sacrificing sensitivity.

\section{EXPERIMENTAL AND DISCUSSION}

\section{(a) Principle of the method}

To test our new method, we used Xenopus insulin mRNA as our target RNA (Shuldiner et al., 1989)(Fig. 1). RS-PCR was accomplished by first reverse transcribing Xenopus pancreatic RNA using a 41-nt oligo as primer (primer $d_{20^{-}} t_{21}$ ) whose sequence contained $20 \mathrm{nt}$ at its $3^{\prime}$ end that were complementary to a region of Xenopus insulin mRNA (segment $d_{20}$ ), and $21 \mathrm{nt}$ at its $5^{\prime}$ end that were unique in sequence (segment $t_{21}$ ) (step 1 in Fig. 1). The resulting ss cDNA, which now contains a unique 21-nt tag at its $5^{\prime}$ end, was separated from excess primer $d_{20}{ }^{-t}{ }_{21}$ by ultrafiltration. The second strand was synthesized during the first cycle of PCR using primer $\mathrm{u}_{21}$, a 21-nt oligo corresponding to Xenopts insulin cDNA 265 bp upstream from the sequence 


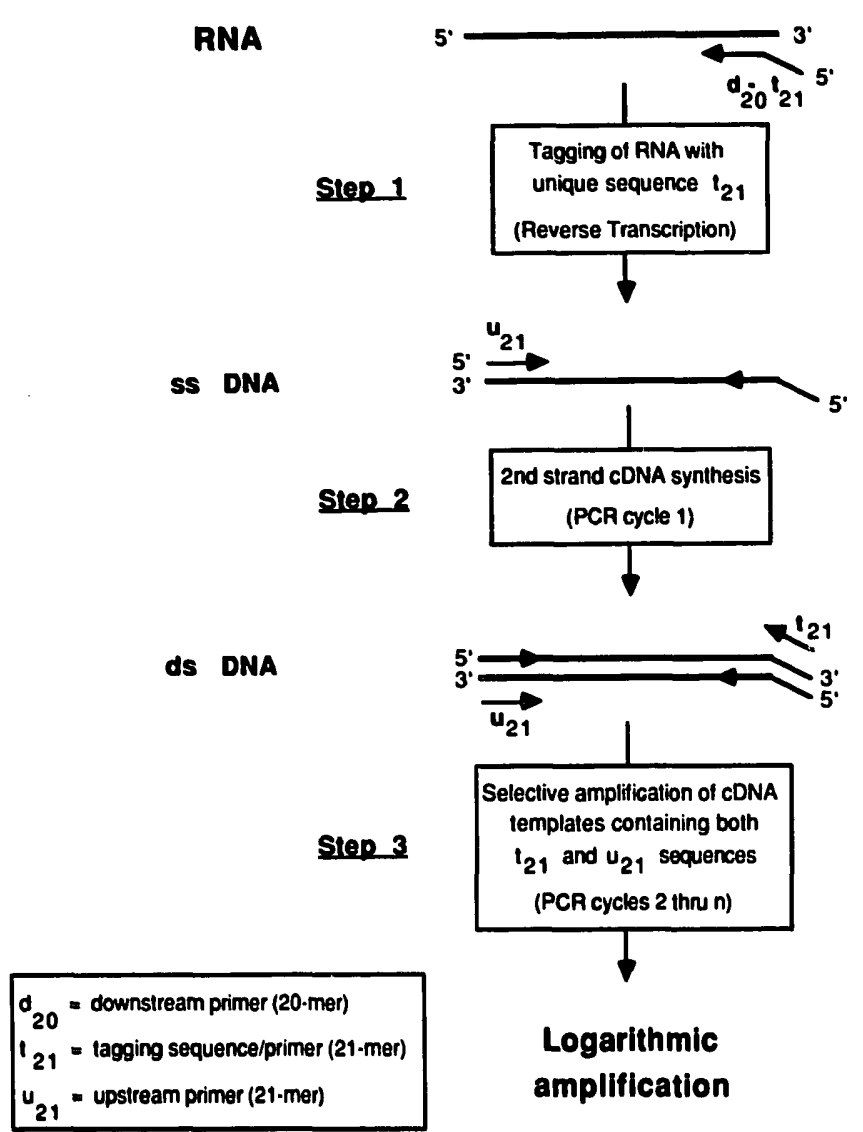

Fig. 1. Outline of RS-PCR. (Step 1) Total RNA from Xenopus pancreatic tissue was prepared and reverse transcribed at $42^{\circ} \mathrm{C}$ for $1 \mathrm{~h}$ in a $25-\mu$ l reaction mixture containing $50 \mathrm{mM}$ Tris $\cdot \mathrm{HCl}$ pH 8.7 at room temperature/100 mM NaCl/6 mM MgCl$/ 10 \mathrm{mM}$ dithiothreitol/1 mM of each dNTP)/1 unit RNasin (Promega, Madison, WI) $0.5 \mu \mathrm{M}$ primer $d_{20^{-t}}$ (5'-GACAAGCTTCAGGTATCGATT-TGCATGATGGAATTGCCTTG-3')/10 units of avian myeloblastosis virus-RT (Promega). Excess primer $d_{20}-t_{21}$ was removed by ultrafiltration through Centricon 100 (Amicon; Danvers, MA) with four successive 2-ml washes. (Step 2) The second strand was synthesized during the first cycle of PCR which was performed in a $50-\mu l$ reaction volume containing $10 \mathrm{mM}$ Tris $\cdot \mathrm{HCl}$ pH 8.3 at room temperature $/ 50 \mathrm{mM} \mathrm{KCl} / 1.5 \mathrm{mM} \mathrm{MgCl}_{2} / 0.1 \mathrm{mg}$ gelatin per $\mathrm{ml} / 1 \mathrm{mM}$ of each dNTP/0.5 $\mu \mathrm{M}$ primer $t_{21}$ (5'-GACAAGCTTCAGGTATCGATT-3')/ $0.5 \mu \mathrm{M}$ primer $u_{21}$ (5'-GAGGCTTCTTCTACT. ACCCTA-3')/1 unit of Taq polymerase (Perkin Elmer-Cetus, Emeryville, CA). (Step 3) PCR, 45 to 60 cycles were performed, each cycle consisting of annealing $\left(55^{\circ} \mathrm{C}, 1.5 \mathrm{~min}\right)$, extension $\left(72^{\circ} \mathrm{C}, 1.5 \mathrm{~min}\right)$ and denaturation $\left(94^{\circ} \mathrm{C}, 1 \mathrm{~min}\right)$; in the first cycle, the denaturation time was increased to $5 \mathrm{~min}$, and in the last cycle, the extension time was increased to $10 \mathrm{~min})$. Reaction mixtures $(20 \mu \mathrm{l})$ were loaded onto a composite gel containing $1 \%$ agarose (Bethesda Research Laboratories, Gaithersburg, MD) and 2\% NuSeive GTG agarose (FMC Bioproducts; Rockland, ME), electrophoresed, stained with ethidium bromide, and visualized by UV transillumination (see Fig. 2). In novel RS-PCR, sequences derived from RNA that had been tagged with the unique sequence $\left(t_{21}\right)$ during RT (step 1) are amplified preferentially during PCR with primers $t_{21}$ and $u_{21}$ (steps 2 and 3), while contaminating DNA, lacking the unique tag are not amplified. By contrast, conventional RT-PCR uses primers whose nt sequences both correspond to the target sequence (primers $d_{20}$ and $u_{21}$ ), and therefore polynucleotide templates derived from either RNA or DNA are amplified equally we!l. (a)

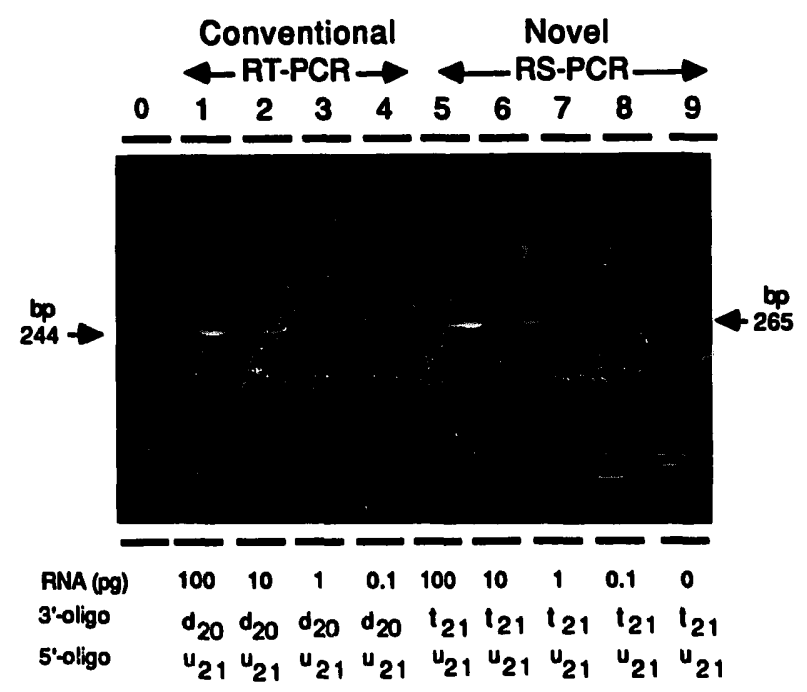

(b)

(c)

\section{Conventional RT-PCR}

Novel RS-PCR
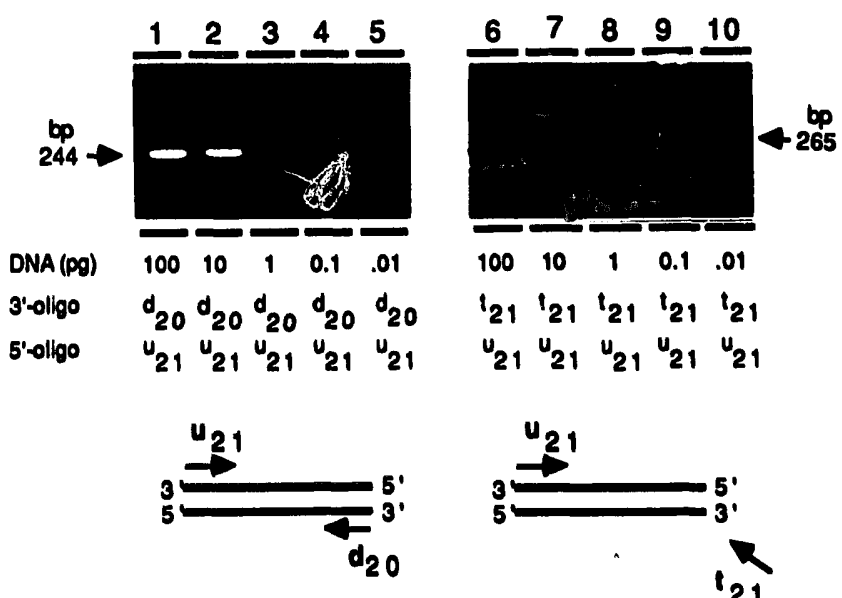
$\begin{array}{lllll}100 & 10 & 1 & 0.1 & .01\end{array}$ $\begin{array}{llllll}t_{21} & t_{21} & t_{21} & t_{21} & t_{21}\end{array}$ $u_{21} u_{21} u_{21} u_{21} u_{21}$

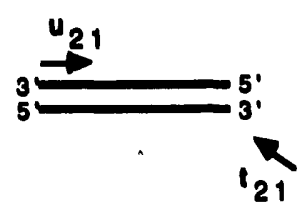

Fig. 2. Comparison of conventional RT-PCR and novel RS-PCR. (Panel a) Conventional RT-PCR (primers $d_{20}$ and $u_{21}$ ) (lanes 1-4) vs. novel RS-PCR (primers $t_{21}$ and $u_{21}$ ) (lanes 5-9) of serial tenfold dilutions of Xenopus pancreatic RNA. Lane 0, HaeIII digest of $\phi$ X174 DNA. (Panels $b$ and c) Comparison of conventional RT-PCR (primers $d_{20}$ and $u_{21}$ ) and novel RS-PCR (primers $t_{21}$ and $u_{21}$ ) when serial tenfold dilutions of Xenopus insulin ds cDNA rather than RNA were used as the starting template to mimic cDNA contamination. In four additional experiments we obtained similar results with approx. 100 - to 10000 -fold difference between the ability of conventional RT-PCR and novel RS-PCR to amplify cDNA contaminants.

corresponding to segment $d_{20}$ (step 2 in Fig. 1). Logarithmic amplification was accomplished during subsequent PCR cycles using primers $t_{21}$ and $u_{21}$ (step 3 in Fig. 1). With this approach, sequences derived from RNA that had been tagged with the unique sequence $\left(t_{21}\right)$ are amplified preferentially, while conta: ninating $\mathrm{NA}$, lacking the unique tag. is not amplified. By' contrast, conventional RT-PCR uses primers whose nt sequences both correspond to the target 
sequence (i.e., primers $d_{20}$ and $u_{21}$ ), and therefore templates derived from either RNA or DNA are amplified equally well.

\section{(b) RS-PCR preferentially amplifies RNA templates}

To test whether RS-PCR was as sensitive as conventional RT-PCR, the two methods were compared starting with small quantities of Xenopus pancreatic RNA. When starting with RNA as template, novel RS-PCR (primers $\mathbf{t}_{21}$ and $u_{21}$ ) was as sensitive as conventional RT-PCR (primers $d_{20}$ and $u_{21}$ ) in amplifying Xenopus insulin mRNA (Fig. 2a). By contrast, when Xenopus insulin full-length ds CDNA was used as template instead of mRNA to mimic DNA contamination, RS-PCR was approx. 100- to 10000-fold less affected than conventional RT-PCR by the presence of DNA contaminants even after 60 cycles (compare Fig. 2,b and c).

In theory, with the RS-PCR method, only RNA that had been primed with primer $d_{20}-t_{21}$ during $R T$ should have been amplified during PCR. However, we found that, when relatively large quantities of DNA template $(>10 \mathrm{pg}$ or approx. $1 \times 10^{7}$ molecules) were used, detectable amplification was observed (lane 6 in Fig. 2c). We have determined from separate experiments that this phenomenon was caused by two mechanisms: $(i)$ at relatively high DNA concentrations, RT acted as a DNA polymerase and incorporated primer $d_{20}-t_{21}$ into the so-called first strand, and (ii) the minute quantities of primer $d_{20}-t_{21}$ that remained behind after ultrafiltration incorporated into DNA during early PCR cycles which could then be amplified efficiently in RS-PCR (data not shown).

We have also determined from separate experiments that, when pancreatic RNA was spiked with Xenopus insulin ds CDNA and the mixture was subjected to RS-PCR, the cDNA did not interfere with the efficient amplification of RNA (data not shown). As expected, when we changed the sequence of the unique 21-nt tag, and purposely introduced DNA amplified in previous experiments that contained a different unique 21-nt tag to mimic carry-over contamination, no amplification was observed (data not shown). During these experiments, despite numerous precautions, we frequently observed false positives when conventional RT-PCR was used. In striking contrast, not a single false positive was observed in over 20 independent experiments when the RS-PCR method was used. We have not yet tested the RS-PCR method with ss DNA contaminants (e.g., M13 recombinants).

\section{(c) Conclusions}

(1) RS-PCR is equally sensitive as conventional RT-PCR when amplifying from an RNA template, and is several orders of magnitude less affected by DNA contaminants. In addition to guarding against contamination from carry-over of exogenous DNA, RS-PCR should also be effective in eliminating false positives from small amounts of genomic DNA that may copurify with RNA; whenever it is not possible to amplify regions that span introns, RS-PCR should prove advantageous over other existing strategies for avoiding adverse consequences of contamination with genomic DNA.

(2) We have found that RS-PCR usually results in a cleaner amplification with fewer side-products, and in several cases, greater sensitivity than conventional RT-PCR. We believe these added benefits of RS-PCR are the result of the ability to tailor the nt sequence of the tagging segment, thereby generating a highly efficient 'model' PCR primer; a primer that is independent of the nt sequence of the target RNA, contains approx. $25 \%$ of each nt, contains no appreciable similarities to other known sequences, no discernible secondary structure, and no selfcomplementarity at its $3^{\prime}$ end with the $3^{\prime}$ end of the upstream primer (Saiki, 1989; Watson, 1989).

\section{ACKNOWLEDGEMENTS}

We thank Simeon I. Taylor, Charles T. Roberts Jr., Eric Ackerman, Marc L. Reitman, Cathy McKeon, Laurie A. Scott, Takashi Kadowaki, Lee S. Weinstein, and Maxine A. Lesniak for their helpful comments on the manuscript, and Neubert Phillippe and Ester Bergman for their clerical assistance. This research project was supported in part by grants from the Washington Affiliate of the American Diabetes Association, the Diabetes Research and Education Foundation, and the Juvenile Diabetes Foundation.

\section{REFERENCES}

Kawasaki, E.S., Clark, S.S., Coyne, M.Y., Smith, S.D., Champlin, R., Witte, O.N. and McCormick, F.P.: Diagnosis of chronic myeloid and acute lymphocytic leukemias by detection of leukemia-specific mRNA sequences amplified in vitro. Proc. Natl. Acad. Sci. USA 85 (1988) 5698-5702.

Kwok, S. and Higuchi, R.: Avoiding false positives with PCR. Nature 339 (1989) 237-238.

Rappolee, D.A., Mark, D., Banda, M.J. and Werb, Z.: Wound macrophages express TGF-alpha and other growth factors in vivo: analysis by mRNA phenotyping. Science 241 (1988a) 708-712.

Rappolee, D.A., Brenner, C.A., Schultz, R., Mark, D. and Werb, Z.: Developmental expression of PDGF, TGF-alpha, and TGF-beta genes in preimplantation mouse embryos. Science 241 (1988b) 1823-1825.

Saiki, R.K.: The design and optimization of the PCR. In Erlich, H.A. (Ed.), PCR Technology. Stockton Press, New York, 1989, pp. 1-16.

Saiki, R.K., Scharf, S., Faloona, F., Mullis, K.B., Horn, G.T., Erlich, H.A. and Arnheim, N.: Enzymatic amplification of beta-globin genomic sequence and restriction site analysis for diagnosis of sickle cell anemia. Science 230 (1985) 1350-1354. 
Shuldiner, A.R., Phillips, S., Roberts Jr., C.T., LeRoith, D. and Roth, J.: Xenopus laevis contains two different nonallelic preproinsulin genes: cDNA cloning and evolutionary perspective. J. Biol. Chem. 264 (1989) 9428-9432.
Watson, R.: The formation of primer artifacts in polymerase chain reaction. In Sawyer, A.L. (Ed.), Amplifications. Perkin Elmer-Cetus, Norwalk, CT, 1989, pp. 5-6. 